\title{
University courses, eating problems and muscle dysmorphia: are there any associations?
}

\author{
Simona Bo ${ }^{1 *}$, Rossana Zoccali ${ }^{1}$, Valentina Ponzo ${ }^{1}$, Laura Soldati ${ }^{2}$, Luca De Carli ${ }^{1}$, Andrea Benso ${ }^{1}$, Elisabetta Fea ${ }^{3}$, \\ Alberto Rainoldi ${ }^{1}$, Marilena Durazzo ${ }^{1}$, Secondo Fassino ${ }^{4}$ and Giovanni Abbate-Daga ${ }^{4}$
}

\begin{abstract}
Background: Orthorexia and muscle dysmorphia are disorders affecting above all young adults whose prevalence and social impact are still unclear. We aimed to evaluate the prevalence of the traits of orthorexia and muscle dysmorphia among freshmen attending university courses focused on nutrition (Dietetics) and body care (Exercise and Sport Sciences). Students of Biology were considered as a control group. The prevalence of eating disorder (ED) traits were also evaluated.

Methods: All participants ( $n=440 ; n=53$ Dietetics school, $n=200$ Exercise and Sport Sciences school, $n=187$ the Biology school) completed the following questionnaires: ORTO-15, Muscle-Dysmorphic-Disorder-Inventory, and Eating Attitudes Test-26.

Results: The prevalence of the traits of EDs, orthorexia, and muscle dysmorphia was 9.1\%, 25.9\%, and 5.9\%, respectively. When compared to other students, those attending the Dietetics school showed a 2-fold higher risk of EDs and those from the Exercise and Sport Sciences school a 10-fold higher risk of muscle dysmorphia. The prevalence of orthorexia traits was high in all schools (35.9\%, 22.5\%, 26.5\% in Dietetics, Biology, and Exercise and Sport Sciences schools, respectively). Overall, individuals with traits of any of these disorders were more frequently on diet or on supplement use. In a logistic regression model, attending the Dietetics school (OR $=2.71 ; 95 \% \mathrm{Cl} 1.14-6.48)$ was significantly associated with the ED traits, but not with the orthorexia traits $(\mathrm{OR}=1.75 ; 95 \% \mathrm{Cl}$ 0.93-3.29), while attending the Exercise and Sport Sciences school was significantly associated with the muscle dysmorphia traits (OR $=5.15$; $95 \% \mathrm{Cl}$ 1.44-18.4). Finally, when evaluating the relationships among the types of study programs as dependent variables and traits of these disturbances, the associations between the traits of $\mathrm{ED}(\mathrm{OR}=3.35 ; 95 \% \mathrm{Cl} 1.38-8.13)$ and matriculation at the school of Dietetics, and between the traits of muscle dysmorphia (OR $=4.32 ; 95 \% \mathrm{Cl} 1.16-16.1$ ) and the choice of the Exercise and Sport Sciences school were confirmed.
\end{abstract}

Conclusions: The choice of the university courses might be influenced by pre-existing disorders in eating behaviors, which were relatively frequent in the considered sample.

Keywords: Eating disorders, Freshmen, Muscle dysmorphia, Orthorexia

\section{Background}

Atypical disorders in eating behaviors are increasingly described in developed countries [1]. Although the DSM-5 has renewed and extended the diagnostic categories, some eating attitudes, such as orthorexia, are still neglected and others, such as muscle dysmorphia, are not extensively considered [2]. The term orthorexia

\footnotetext{
* Correspondence: simona.bo@unito.it

'Department of Medical Sciences, University of Turin, C.so AM Dogliotti 14, 10126 Turin, Italy

Full list of author information is available at the end of the article
}

was first used in 1997 by Bratman to describe an obsession for healthy nutrition [3], characterized by an excessive and time-consuming preoccupation with healthy eating [4]. At present, orthorexia is not a formal disorder, but rather a healthy attitude: only in extreme cases, the obsessive characteristics of orthorexia become pathological, leading to a very restrictive diet with the avoidance of many foods considered to be harmful [5] and to social isolation [6]. There is no consensus either on the categorization of othorexia among mental disorders or even if it is a mental disorder, therefore it should be 
considered at present a controversial concept [7]. Furthermore, no comprehensive and standardized criteria for orthorexia exist [8]. The average prevalence of orthorexia, defined by Donini et al. as an attitude with obsessive-compulsive personality features plus a "fanatic" healthy eating habits, is $6.9 \%$ in the general population [4], and $35-58 \%$ in high-risk groups (healthcare professionals, such as dieticians, and artists) [8]. Among dieticians, $12.8 \%$ showed orthorexia and $34.9 \%$ some orthorectic behaviors [9]; therefore, it has been hypothesized that a disordered eating attitude might be a motivation to start a nutrition study program to cope with it [9]. Indeed, no difference for orthorexia nervosa, but only for dietary restrain were found between students attending a university course of nutrition science and the control group [10]. Finally, a great deal of controversy surrounding the notion that orthorexia is a valid nosological entity exists $[11,12]$.

Muscle dysmorphia was first described in 1993 by Pope and coll. [13] as an obsessive-compulsive disorder, characterized by the obsession of body appearance, the fear of not being sufficiently muscled, and the compulsion to excessive physical exercise [14]. Such individuals show changes in feeding behavior, such as radical diets and dietary supplements, abuse of anabolic substances, and impairment or distress in social and physical domains [15], and in social and occupational functioning $[16,17]$. According to the DSM-5, the specification "with muscle dysmorphia" has been added to body dysmorphic disorder, suggesting that this is an important distinction to be done as regards this disorder. Muscle dysmorphia is more frequently diagnosed in male young adults $[14,18]$, and bodybuilders represent a high-risk group [19]. The prevalence of muscle dysmorphia in the general population is still unknown since only few small studies are available [20]. We wonder if students from schools oriented to fitness and body care show an increased prevalence of the traits of this disorder.

Therefore, orthorexia and muscle dysmorphia seem to be attitudes with a potentially high social impact, mostly affecting young adults. We hypothesized that some students could choose a university course oriented on healthy food and healthy body, because they have a pre-existent peculiar eating behavior or pre-existing muscle dysmorphia traits. Indeed, a few studies have shown that personality traits, motivations, and lifestyle habits might correlate with the choice of the future profession [21-23]. In particular, we hypothesized that students matriculating at the school of Dietetics showed an increased prevalence of orthorexia and eating disorder (ED) traits, while those matriculating at the Exercise and Sport Sciences school showed an increased prevalence of muscle dysmorphia. The school of Biology is not specifically oriented to the body care or nutrition in Italy; we hypothesized that freshmen from this school showed a lower prevalence of all these traits.

The aim of the present study was therefore to investigate whether the prevalence of the traits of orthorexia, muscle dysmorphia, and EDs might differ among freshmen attending the schools of Dietetics and Exercise and Sport Sciences. These data were compared with those obtained from the freshmen of the school of Biology, as a control group.

\section{Methods \\ Participants}

All freshmen applying in fall 2012 to the school of Dietetics $(n=32)$, Exercise and Sport Sciences $(n=230)$, and Biology $(n=227)$ at the University of Turin were contacted. Owing to the low number of freshmen from Dietetics, those who matriculated in fall $2013(n=28)$ were also approached for the purposes of this study. Only the students who were about to start the different majors were considered. The students who gave their informed consent to participate were: 53/60 (88.3\%), 200/230 (87.0\%), and 187/227 (82.4\%) from Dietetics, Exercise and Sport Sciences and Biology schools, respectively.

The study protocol was approved by the local Ethics Committee (University of Turin Bioethical Committee), and all procedures were in line with the Helsinky Declaration.

\section{Measures}

All participants completed 4 anonymous questionnaires. The participants provided information on age, gender, ethnicity, use of drugs, dietary supplements, specific diets, and exercise level (hours/week) in the first questionnaire.

Freshmen attending Dietetics school were also asked to report their weight and height values.

The second questionnaire was the ORTO-15 test, one of the tools used to assess orthorexia [24]. This is a 15items questionnaire, with questions rated on a 4-point scale (ranging from "never" to "always"), investigating the obsessive attitude towards the choice, preparation, and consumption of healthy foods. A lower score value ("1") was given to the answers indicating orthorexia, while the healthier ones had a score of "4". The sum of the points was the final score of the test; the cutoff score of $<35$ points showed high specificity $(94.2 \%)$ and negative predictive value (91.1\%) [24]. The MDDI (The Muscle Dysmorphic Disorder Inventory) was the third questionnaire; it is a 13-item tool for the diagnosis of muscle dysmorphia, containing questions on cognitions, emotions, and behaviors related to body image [25]. Items are rated on a 5-point scale, ranging from "never" to "always"; the score of the test is the sum of the scores of each item. The threshold value $>39$ points showed $75 \%$ specificity and $73.7 \%$ sensitivity [26], with a Cronbach alpha coefficient $=0.85$ in an Italian validation study [27]. 
The fourth questionnaire was the Eating Attitudes Test-26 (EAT-26), which is a widely used self-report standardized tool investigating symptoms and concerns characteristic of EDs. It is a refinement of the original EAT-40 [28]. Participants were required to judge whether "very often", "often", "rarely", "sometimes" or "never" applied to each of the 26-items. A score $\geq 20$, which is the sum of the points of each item, is considered to be predictive of the risk of EDs; the Cronbach alpha coefficient for EAT-26 is 0.86 [29]. EAT-26 is considered a highly reliable and valid instrument [30]; however, further clinical evaluations are required in order to make a correct diagnosis [31].

\section{Statistical analyses}

All data are presented as mean \pm standard deviation or percentage. Questionnaires scores and exercise levels were not normally distributed and were log-transformed, thus obtaining a normal distribution. In all the analyses the log-values were used. To improve the ease of interpretation, non-transformed values are shown.

ANOVA and $x^{2}$-test were used to assess the differences among groups for continuous and categorical variables, respectively. A post-hoc analysis was performed using Scheffè's test.

A multiple logistic regression model was used to evaluate the association between the traits of ED, orthorexia and muscle dysmorphia (dependent variables), and age, gender, exercise, and the attended school. Further logistic regression analyses were performed, using two dummy coded variables in each of the models (i.e., those who matriculated at Dietetics got a score of 1 and everyone else received a 0 score, and those who majored in Exercise and Sport Sciences received a score of 1 and all others received a score of 0 ).

Finally, the association among the matriculation at the schools of Dietetics, Exercise and Sport Sciences, Biology (dependent variables) and the traits of ED, orthorexia, muscle dysmorphia and the respective scores, used as continuous variables was assessed by a logistic regression analysis, adjusted for age, sex, and log-exercise. One model for each variable was performed.

The $\mathrm{p}$-values obtained with the likelihood ratio test with respect to the null model were given (STATISTICA software 5.1, Statsoft Italia).

\section{Results}

The characteristics of the sample are reported in Table 1. Those attending the Dietetics school were more frequently dieting, and showed a more than 2-fold higher likelihood of EDs than other students. The students attending the Exercise and Sport Sciences school were more frequently highly exercising males on dietary supplements, and showed a 10-fold higher likelihood of
Table 1 Characteristics of the students grouped by school

\begin{tabular}{lllll}
\hline & Dietetics & Biology & $\begin{array}{l}\text { Exercise and } \\
\text { Sport Sciences }\end{array}$ & $\mathbf{P}$ \\
\hline Number & 53 & 187 & 200 & \\
Males (\%) & 22.6 & $29.4 \# \#$ & $67.5 \S \S$ & $<0.001$ \\
Age (years) & $19.8 \pm 2.7$ & $19.7 \pm 1.4$ & $19.9 \pm 1.8$ & 0.62 \\
Exercise (h/week) & $4.4 \pm 2.8$ & $3.6 \pm 2.6 \# \#$ & $12.0 \pm 6.5 \S \S$ & $<0.001$ \\
Score EAT-26 & $9.5 \pm 8.1$ & $9.3 \pm 8.3$ & $8.3 \pm 7.5$ & 0.41 \\
Score oral control & $1.7 \pm 2.6$ & $1.4 \pm 2.2$ & $1.3 \pm 2.3$ & 0.55 \\
Score bulimia & $2.1 \pm 2.1$ & $1.8 \pm 2.3$ & $1.6 \pm 2.3 \S$ & 0.04 \\
Score dieting & $5.8 \pm 4.9$ & $5.8 \pm 4.9$ & $5.6 \pm 4.9$ & 0.80 \\
Traits of ED (\%) & $18.9^{*}$ & 8.6 & $7.0 \S \S$ & 0.03 \\
Score orthorexia & $37.2 \pm 4.6$ & $38.7 \pm 4.8$ & $38.6 \pm 5.2$ & 0.13 \\
Traits of orthorexia (\%) & 35.9 & 22.5 & 26.5 & 0.14 \\
Score muscle & $23.3 \pm 5.8$ & $22.2 \pm 9.6 \# \#$ & $28.9 \pm 7.2 \S \S$ & $<0.001$ \\
dysmorphia & & & & $<0.001$ \\
Traits of muscle & 1.9 & $1.6 \# \#$ & $11.0 \S$ & 0.002 \\
dysmorphia (\%) & & & & 0.12 \\
Supplement use (\%) & 5.7 & $7.5 \# \#$ & $18.0 \S$ & 8.0 \\
Dieting (\%) & 15.1 & 6.4 & &
\end{tabular}

* $p<0.05$ Dietetics vs Biology.

$\S \mathrm{p}<0.05$ Dietetics vs Exercise and Sport Science.

$\S \S p<0.01$ Dietetics vs Exercise and Sport Sciences.

$\# \#$ $<0.01$ Biology vs Exercise and Sport Science.

having muscle dysmorphia. The prevalence of students with traits of EDs, orthorexia, and muscle dysmorphia was $9.1 \%, 25.9 \%$, and $5.9 \%$, respectively. However, the distribution of these students among schools was highly asymmetrical (Tables 1 and 2). In particular, most students with traits of muscle dysmorphia attended the Exercise and Sport Sciences school. A gender-distribution emerged amongst students with traits of EDs (mainly females) and of muscle dysmorphia (mainly males), but not for those with traits of orthorexia. Students with traits of EDs were significantly older (Table 2). Overall, individuals with traits of any of these disorders were more frequently on diet (above all students with EDs traits) or on supplement use (above all students with muscle dysmorphia traits). Among students at risk of EDs, $66.7 \%$ declared to be on a hypocaloric diet, $16.7 \%$ on a vegetarian and $16.7 \%$ on a hyperproteic regimen ( $\mathrm{p}=0.048$ ). With respects to dieters, $45.5 \%, 27.3 \%$, and $27.3 \%$ of those with traits of orthorexia and $22.2 \%, 33.3 \%$, and $44.4 \%$ of those with traits of muscle dysmorphia were on hypocaloric, vegetarian, and hyperproteic diets, respectively. Furthermore, individuals with traits of any disorders were more frequently at risk of another disorder (Table 2).

Weight and height of the Dietetics school students $(n=53)$ were self-reported. Mean weight and BMI of students with traits of EDs $(n=10)$ were $47.0 \pm 3.9 \mathrm{~kg}$ and $16.9 \pm 1.6 \mathrm{~kg} / \mathrm{m}^{2}$ while the corresponding values of 
Table 2 Characteristics of the students according to the questionnaires

\begin{tabular}{|c|c|c|c|}
\hline Traits of ED & Yes $(n=40)$ & No $(n=400)$ & $\mathbf{P}$ \\
\hline Males (\%) & 17.5 & 49.8 & $<0.001$ \\
\hline Age (years) & $20.8 \pm 1.8$ & $19.7 \pm 1.7$ & $<0.001$ \\
\hline Exercise (h/week) & $7.9 \pm 3.6$ & $7.5 \pm 6.5$ & 0.69 \\
\hline School: Dietetics & 25.0 & 10.8 & \\
\hline Biology & 40.0 & 42.8 & \\
\hline Exercise and Sport Sciences & 35.0 & 46.5 & 0.03 \\
\hline Supplement use (\%) & 20.0 & 11.3 & 0.11 \\
\hline Dieting (\%) & 45.0 & 4.5 & $<0.001$ \\
\hline Traits of orthorexia (\%) & 70.0 & 21.5 & $<0.001$ \\
\hline Traits of muscle dysmorphia (\%) & 15.0 & 5.0 & 0.01 \\
\hline Traits of orthorexia & Yes $(n=114)$ & No $(n=326)$ & $\mathbf{P}$ \\
\hline Males (\%) & 40.4 & 49.1 & 0.11 \\
\hline Age (years) & $20.1 \pm 1.5$ & $19.7 \pm 1.8$ & 0.10 \\
\hline Exercise (h/week) & $7.9 \pm 5.7$ & $7.4 \pm 6.5$ & 0.40 \\
\hline School: Dietetics & 16.7 & 10.4 & \\
\hline Biology & 36.8 & 44.5 & \\
\hline Exercise and Sport Sciences & 46.5 & 45.1 & 0.14 \\
\hline Supplement use (\%) & 19.3 & 9.5 & 0.006 \\
\hline Dieting (\%) & 19.3 & 4.3 & $<0.001$ \\
\hline Traits of ED (\%) & 24.6 & 3.7 & $<0.001$ \\
\hline Traits of muscle dysmorphia (\%) & 9.7 & 4.6 & 0.05 \\
\hline Traits of muscle dysmorphia & Yes $(n=26)$ & No $(n=414)$ & $\mathbf{P}$ \\
\hline Males (\%) & 73.1 & 45.2 & 0.006 \\
\hline Age (years) & $20.2 \pm 1.8$ & $19.8 \pm 1.7$ & 0.31 \\
\hline Exercise (h/week) & $11.9 \pm 7.7$ & $7.3 \pm 6.1$ & $<0.001$ \\
\hline School: Dietetics & 3.8 & 12.6 & \\
\hline Biology & 11.5 & 44.4 & \\
\hline Exercise and Sport Sciences & 84.6 & 43.0 & $<0.001$ \\
\hline Supplement use (\%) & 61.5 & 8.9 & $<0.001$ \\
\hline Dieting (\%) & 30.8 & 6.8 & $<0.001$ \\
\hline Traits of ED (\%) & 23.1 & 8.2 & 0.01 \\
\hline Traits of othorexia (\%) & 42.3 & 24.9 & 0.05 \\
\hline
\end{tabular}

students without traits $(n=43)$ were $64.7 \pm 12.7 \mathrm{~kg}$ and $22.4 \pm 3.3 \mathrm{~kg} / \mathrm{m}^{2}$ (gender- and age-adjusted $\mathrm{p}$ values were $<0.001$ for both weight and BMI).

The association between disorders and the school choice was evaluated in a logistic regression model, after adjusting for age, gender, and exercise level (Table 3). Female gender $(\mathrm{OR}=0.15$; 95\% CI $0.06-0.39$ for male gender), age ( $\mathrm{OR}=1.38$; 95\% CI 1.15-1.66), and attending the Dietetics school (OR $=2.71 ; 95 \%$ CI 1.14-6.48) resulted significantly associated with the likelihood of having EDs (Table 3), but not with the likelihood of orthorexia. Both male gender and exercise level were significantly associated with the likelihood of having muscle dysmorphia at univariate analysis; these associations disappeared in a multivariate regression analysis, after introducing into the model the matriculation at the Exercise and Sport Sciences school which resulted the only variable to be significantly associated with the likelihood of muscle dysmorphia (OR $=5.15 ; 95 \%$ CI 1.44-18.4) (Table 3).

By using both the school of Dietetics and the school of Exercise and Sport Sciences as two dummy variables in the logistic regression analyses, matriculating at the Dietetics school was significantly associated with traits of EDs (OR $=2.54$; 95\% CI 1.02-6.40; p = 0.04) and matriculating at the school of Exercise and Sport Sciences was associated with traits of muscle dysmorphia $(\mathrm{OR}=4.62$; 95\% CI 1.15-18.6; $\mathrm{p}=0.03$ ).

Finally, when evaluating the relationships among the types of study programs as dependent variables (Table 4) and traits or scores of the three disturbances, the associations between the traits of ED (OR $=3.35$; 95\% CI 1.388.13) and the bulimia score (OR $=1.10 ; 95 \%$ CI 1.02-1.22) with matriculation at the school of Dietetics were confirmed, while the associations between orthorexia traits $(\mathrm{OR}=1.87 ; 95 \%$ CI 1.00-3.52) and score $(\mathrm{OR}=0.94$; 95\% CI 0.88-1.00) and this school resulted borderline (Table 4). Furthermore, the associations between muscle dysmorphia traits (OR $=4.32$; 95\% CI 1.16-16.1) and score $(\mathrm{OR}=1.07$; 95\% CI 1.02-1.13) and the choice of the Exercise and Sport Sciences school were confirmed too. An inverse association between the muscle dysmorphia score and the choice of the Biology school was found.

\section{Discussion}

The prevalence of EDs traits was high among female freshmen attending the school of Dietetics, while that of muscle dysmorphia traits was higher among males attending the Exercise and Sport Sciences school, as expected. Contrarily to our hypothesis, orthorexia was a condition for which about one fourth of the students across different schools were at risk, without a clear gender distribution.

Only few studies are available on this topic. A European survey found that $12.8 \%$ of dieticians showed symptoms of orthorexia and reported a previous or current ED, such as anorexia nervosa, bulimia nervosa or binge eating disorder [9]. Accordingly, we found that about one fifth of students attending the school of Dietetics showed traits of EDs. Our results were higher than those reported in another Italian study where a $5.5 \%$ prevalence was found in high-school students in Turin [32]. Therefore, female students attending the Dietetics school could be at greater risk for EDs than younger females [9]. Indeed, our prevalence of individuals with traits of ED attending the Exercise and Sport Sciences and Biology schools was 
Table 3 Conditions associated with traits of EDs, orthorexia and muscle dysmorphia in a multiple logistic regression model

\begin{tabular}{|c|c|c|c|c|c|c|c|}
\hline Traits of eating disorders & $\beta$ & SE $\beta$ & Wald & $\mathbf{P}$ & OR & $95 \% \mathrm{Cl}$ & $P^{* *}$ \\
\hline Age & 0.32 & 0.09 & 11.8 & 0.001 & 1.38 & $1.15-1.66$ & \\
\hline Males & -1.87 & 0.47 & 15.7 & $<0.001$ & 0.15 & $0.06-0.39$ & \\
\hline Exercise* & 0.69 & 0.39 & 3.13 & 0.08 & 1.99 & $0.93-4.31$ & \\
\hline School of Dietetics & 1.00 & 0.44 & 5.09 & 0.02 & 2.71 & $1.14-6.48$ & $<0.001$ \\
\hline \multicolumn{8}{|l|}{ Traits of orthorexia } \\
\hline Age & 0.11 & 0.06 & 3.09 & 0.08 & 1.11 & $0.99-1.26$ & \\
\hline Males & -0.43 & 0.23 & 3.39 & 0.07 & 0.65 & $0.41-1.03$ & \\
\hline Exercise* $^{*}$ & 0.34 & 0.25 & 1.90 & 0.17 & 1.41 & $0.86-2.29$ & \\
\hline School of Dietetics & 0.56 & 0.32 & 3.01 & 0.08 & 1.75 & 0.93-3.29 & 0.04 \\
\hline \multicolumn{8}{|l|}{ Traits of muscle dysmorphia } \\
\hline Age & 0.07 & 0.10 & 0.53 & 0.47 & 1.08 & $0.88-1.31$ & \\
\hline Males & 0.59 & 0.48 & 1.48 & 0.22 & 1.80 & $0.70-4.63$ & \\
\hline Exercise $^{*}$ & 0.20 & 0.48 & 0.19 & 0.67 & 1.23 & $0.48-3.13$ & \\
\hline School of Exercise and Sport Sciences & 1.64 & 0.65 & 6.39 & 0.01 & 5.15 & $1.44-18.4$ & $<0.001$ \\
\hline
\end{tabular}

*Higher quartile of exercise vs the lower quartiles; ${ }^{* *} \mathrm{p}$-values of the likelihood ratio test.

similar to that shown by the aforementioned Italian study [32]. Furthermore, adults might be more likely to report their eating problems than adolescents.

Another German cross-sectional study found that students attending higher semesters of Universities in nutrition sciences had lower scores on dietary restraint than younger students, and that they adopted slightly more healthy food choices [10]. Similar results were found in an US study among students enrolled in Dietetics, which found that junior and senior majors have more positive eating patterns than freshmen as a result of their increased exposure to nutritional information [9]. Our results confirmed the hypothesis that individuals with pre-existing pathological eating behaviours may be inclined to attend the school of Dietetics.

In our study, we found that students of Dietetics with traits of EDs were older than those without these traits. The age range of EDs onset is 18-20 years, but a later onset has been described [33]. The students of the Exercise and Sport Sciences school showed a more than 5 -fold increased adjusted risk of muscle dysmorphia. Most literature on this topic focused on bodybuilders and weightlifters who represent the groups at greatest risk of muscle dysmorphia [34]. An early research proposed that up to $10 \%$ of bodybuilders may be afflicted by this disorder [19], but it is difficult to estimate the prevalence of muscle dysmorphia among the general population and only few studies included mixed-gender samples [20]. It is widely accepted that this condition is substantially a male disturbance; however, it can also affect women [35], and other studies did not find significant differences between genders [36]. We found 7/26 (27\%) female students with these traits and this finding seems worth further studying with larger samples to analyze whether affected girls show any specific behavior and different psychopathological patterns. For example, all females with traits of muscle dysmorphia in our sample were on diet, while the corresponding males reported to be on ergogenic supplement use. Accordingly, individuals with muscle dysmorphia are described to abuse of anabolic-androgenic steroids and supplements, such as protein, amino acids and vitamins [17,37]. It is possible that females at risk of muscle dysmorphia show some psychological traits similar to those of females at risk for EDs, while males at risk are characterized by obsessivecompulsive traits [34]. Indeed, different clinical forms of muscle dysmorphia and the frequent co-presence of an ED in dysmorphic females have been described by the DSM-5 [2]. Further studies are needed to clarify these psychopathological issues. Intriguingly, we found an inverse association between the score of muscle dysmorphia and the school of Biology, thus confirming the relationship between some disturbances and the selection or exclusion of the schools.

Orthorexia was the most frequent disturbance in our cohort. The prevalence we obtained (about 25\%) was higher than that found in the general population (about 7\%) [25], but in line with previous results deriving from high-risk groups [8]. Studies on specific subgroups reported prevalence greater than ours: $45 \%$ among medical doctors [5], and 56\% among performance artists (opera singers, ballet dancers, and musicians) [38]. No significant difference by gender emerged among our students with orthorexia traits, contrarily to literature where either a male $[25,39]$ or a female [40] predominance were found. Contrarily to our hypothesis, the prevalence of the 
Table 4 Association between the type of study program and the traits of EDs, orthorexia and muscle dysmorphia in a multiple logistic regression model*

\begin{tabular}{|c|c|c|c|c|c|c|c|}
\hline School of Dietetics & B & SE $\beta$ & Wald & $\mathbf{P}$ & OR & $95 \% \mathrm{Cl}$ & $\mathbf{p}^{* *}$ \\
\hline Traits of ED & 1.21 & 0.45 & 7.25 & 0.007 & 3.35 & $1.38-8.13$ & $<0.001$ \\
\hline Score EAT-26 & 0.01 & 0.02 & 0.35 & 0.56 & 1.01 & $0.97-1.05$ & 0.009 \\
\hline Score oral control & 0.04 & 0.06 & 0.53 & 0.47 & 1.04 & $0.93-1.18$ & 0.009 \\
\hline Score bulimia & 0.10 & 0.05 & 3.75 & 0.04 & 1.10 & $1.02-1.22$ & 0.005 \\
\hline Score dieting & 0.01 & 0.03 & 0.20 & 0.66 & 1.01 & $0.95-1.08$ & 0.01 \\
\hline Traits of orthorexia & 0.62 & 0.32 & 3.75 & 0.05 & 1.87 & $1.00-3.52$ & 0.002 \\
\hline Score orthorexia & -0.06 & 0.03 & 4.32 & 0.05 & 0.94 & $0.88-1.00$ & 0.002 \\
\hline Traits of muscle dysmorphia & -0.87 & 1.04 & 0.70 & 0.40 & 0.42 & $0.05-3.26$ & 0.007 \\
\hline Score muscle dysmorphia & -0.01 & 0.02 & 0.35 & 0.55 & 0.99 & $0.95-1.03$ & 0.009 \\
\hline \multicolumn{8}{|c|}{ School of Exercise and Sport Sciences } \\
\hline Traits of ED & -0.48 & 0.35 & 1.91 & 0.17 & 0.62 & $0.31-1.22$ & $<0.001$ \\
\hline Score EAT-26 & -0.02 & 0.01 & 1.86 & 0.17 & 0.98 & $0.96-1.01$ & $<0.001$ \\
\hline Score oral control & -0.03 & 0.05 & 0.29 & 0.59 & 0.97 & $0.88-1.08$ & $<0.001$ \\
\hline Score bulimia & -0.08 & 0.05 & 3.43 & 0.06 & 0.92 & $0.84-1.01$ & $<0.001$ \\
\hline Score dieting & -0.03 & 0.02 & 1.95 & 0.16 & 0.97 & $0.92-1.01$ & $<0.001$ \\
\hline Traits of orthorexia & -0.16 & 0.30 & 0.29 & 0.59 & 0.85 & $0.47-1.53$ & $<0.001$ \\
\hline Score orthorexia & 0.01 & 0.03 & 0.32 & 0.57 & 1.01 & $0.96-1.07$ & $<0.001$ \\
\hline Traits of muscle dysmorphia & 1.46 & 0.67 & 4.79 & 0.03 & 4.32 & $1.16-16.1$ & $<0.001$ \\
\hline Score muscle dysmorphia & 0.10 & 0.01 & 12.8 & $<0.001$ & 1.07 & $1.02-1.13$ & $<0.001$ \\
\hline \multicolumn{8}{|l|}{ School of Biology } \\
\hline Traits of ED & 0.26 & 0.40 & 0.44 & 0.51 & 1.30 & $0.60-2.84$ & $<0.001$ \\
\hline Score EAT-26 & 0.01 & 0.01 & 0.89 & 0.35 & 1.01 & $0.98-1.04$ & $<0.001$ \\
\hline Score oral control & 0.01 & 0.05 & 0.03 & 0.86 & 1.01 & $0.92-1.11$ & $<0.001$ \\
\hline Score bulimia & 0.04 & 0.04 & 1.10 & 0.29 & 1.05 & $0.96-1.14$ & $<0.001$ \\
\hline Score dieting & 0.04 & 0.02 & 2.46 & 0.12 & 1.04 & $0.99-1.08$ & $<0.001$ \\
\hline Traits of orthorexia & -0.19 & 0.27 & 0.51 & 0.48 & 0.82 & $0.48-1.40$ & $<0.001$ \\
\hline Score orthorexia & 0.02 & 0.02 & 0.43 & 0.51 & 1.02 & $0.97-1.07$ & $<0.001$ \\
\hline Traits of muscle dysmorphia & -1.08 & 0.68 & 2.58 & 0.11 & 0.34 & $0.09-1.28$ & $<0.001$ \\
\hline Score muscle dysmorphia & -0.05 & 0.02 & 7.97 & 0.005 & 0.95 & $0.92-0.98$ & $<0.001$ \\
\hline
\end{tabular}

${ }^{*}$ Multiple logistic regression model, adjusted for age, sex, log-exercise (one model for each row); ${ }^{* *}$-values of the likelihood ratio test.

orthorexia traits was high in the control group, namely the students attending the school of Biology. The boundaries between healthy and pathological might be more difficult to be defined for the orthorectic attitude and it may represent a consequence of the greater attention to the nutritional education in the youths occurring in recent years, given the uniform distribution of this attitude among schools. Finally, at present, this entity is far from being well defined and characterized, and more specific criteria or validated tools for its diagnosis are needed.

EDs, muscle dysmorphia, and orthorexia are different conditions; in accordance with the DSM-5 classification muscle dysmorphia has been classified as an obsessivecompulsive disorder (i.e. not an ED), while at present orthorexia has not been included at all. However, in our cohort these attitudes were frequently associated, particularly orthorexia and EDs. Indeed, even if these disorders are different, the latter two are both characterized by a common problem: a controlled feeding behavior [41].

\section{Limitations}

This study suffers from several limitations. It is an observational study and the possibility of residual confounding cannot be excluded. Anthropometric variables were not measured; in the subgroup of students from the Dietetics school, however, the referred values of weight and the calculated BMI corresponded to the EDs traits. No psychiatric evaluation was performed, data were obtained by self-report questionnaires and not all the used tools have received an appropriate validation. Indeed, 
our results were consistent with clinical and literature data. For example, the findings that two thirds of our students with ED traits declared to be on a hypocaloric diet and most of those with muscle dysmorphia traits were on hyperproteic diets seem to confirm that diet behaviors are more frequently associated with restrictive or selective feedings $[36,42]$. Dieting is a well known risk factor for EDs [43], but it is important not to pathologize it in the absence of other risk factors, because only $1 \%$ of the dieting adolescents will develop an ED [43,44].

We cannot exclude that a cohort effect due to the assessment of the freshmen from the Dietetic school in the year 2012 and 2013 might exist and impact on the associations found. Furthermore, caution should be exercised in interpreting the finding of this study, owing to the low number of subjects studied. Larger studies may be needed to generate more precise findings; data relative to schools unrelated to the study of the living organism might be interesting too.

Finally, our results may be culture-specific and might not be applicable to other cultures or ethnic groups.

\section{Conclusion}

The choice of the University courses might be influenced by pre-existing disorders in eating behaviors. These results are worthy to be confirmed in larger and longitudinal studies, because of their health implications and of the preventive measures potentially required.



\section{Competing interests}

The authors declare that they have no competing interests.

\begin{abstract}
Authors' contribution
SB participated in the conception and design of the study, supervision of data collection, data analysis, interpretation of the findings of the study, manuscript writing and revision. RZ participated in the data analysis, interpretation of the findings, manuscript writing and revision. VP participated in the data collection, interpretation of the findings, and manuscript revision. LS participated in the interpretation of the findings, and manuscript revision. LDC participated in the data analysis, interpretation of the findings of the study and manuscript revision. $A B$ participated in the data collection, interpretation of the findings of the study and manuscript revision. EF participated in the data analysis, interpretation of the findings of the study and manuscript revision. AR participated in the data collection, interpretation of the findings of the study and manuscript revision. MD participated in the data analysis, interpretation of the findings of the study and manuscript revision. SF participated in the interpretation of the findings of the study, manuscript writing and revision. GAD participated in the conception and design of the study, interpretation of the findings of the study, manuscript writing and revision. All authors have read and approved the final manuscript.
\end{abstract}

\section{Acknowledgements}

We are indebted to Dr. Enrica Marzola for her precious assistance in the English revision.

\section{Author details}

'Department of Medical Sciences, University of Turin, C.so AM Dogliotti 14, 10126 Turin, Italy. ${ }^{2}$ Department of Health Sciences, University of Milan, Milan, Italy. ${ }^{3}$ Department of Public Health and Paediatric Science, University of Turin, P.zza Polonia 94, 10126 Turin, Italy. ${ }^{4}$ Department of Neuroscience, University of Turin, via Cherasco 15, 10126 Turin, Italy.

Received: 5 June 2014 Accepted: 28 July 2014

Published: 7 August 2014

\section{References}

1. Walker DC, Anderson DA, Hildebrandt T: Body checking behaviors in men. Body Image 2009, 6:164-170.

2. American Psychiatric Association: Diagnostic and Statistical Manual of Mental Disorders. DSM-5. 5th edition. Arlington, VA, USA: American Psychiatric Publishing; 2013

3. Bratman S, Knight D: Health Food Junkies: Orthorexia Nervosa- Overcoming the Obsession with Healthful Eating. New York: Brodway Books; 2000.

4. Donini LM, Marsili D, Graziani MP: Orthorexia nervosa: a preliminary study with a proposal for diagnosis and an attempt to measure the dimension of the phenomenon. Eat Weight Disord 2004, 9:151-157.

5. Bağci Bosi AT, Camur D, Güler C: Prevalence of orthorexia nervosa in resident medical doctors in the faculty of medicine (Ankara, Turkey). Appetite 2007, 49:661-666.

6. Bartrina JA: Orthorexia or when the healthy diet becomes an obsession. Arch Latin Nutr 2007, 57:313-315.

7. Varga M, Thege BK, Dukay-Szabó S, Túry F, van Furth EF: When eating healthy is not healthy: orthorexia nervosa and its measurement with the ORTO-15 in Hungary. BMC Psychiatry 2014, 14:59.

8. Varga M, Durkay-Szabò S, Tùry F, van Furth EF: Evidence and gaps in literature in orthorexia nervosa. Eat Weight Disord 2013, 18:103-111.

9. Kinzl JF, Hauer K, Traweger C, Kiefer I: Orthorexia nervosa in dieticians. Psychother Psychosom 2006, 75:395-396.

10. Korinth $A$, Schiess $S$, Westenhoefer J: Eating behaviour and eating disorders in students of nutrition sciences. Public Health Nutr 2010, 13:32-37.

11. Vandereycken W: Media hype, diagnostic fad or genuine disorder? Professionals' opinions about night eating syndrome, orthorexia, muscle dysmorphia, and emetophobia. Eat Disord 2011, 19:145-155.

12. Brytek-Matera A: Orthorexia nervosa - an eating disorder, obsessivecompulsive disorder or disturbed eating habit? Arch Psych Psych 2012, 1:55-60.

13. Pope HG Jr, Katz DL, Hudson J: Anorexia nervosa and "reverse anorexia" among 108 male bodybuilders. Compr Psychiatry 1993, 34:406-409.

14. González-Martí I, Bustos JG, Jordán OR, Mayville SB: Validation of a Spanish version of the Muscle Appearance Satisfaction Scale: escala de satisfacción muscular. Body Image 2012, 9:517-523.

15. Pope HG, Gruber AJ, Mangweth B, Bureau B, de Col C, Jouvent R, Hudson Jl: Body image perception among men in three countries. Am J Psychiatry 2000, 157:1297-1301.

16. Pope CG, Pope HG, Menard W, Fay C, Olivardia R, Phillips KA: Clinical features of muscle dysmorphia among males with body dysmorphic disorder. Body Image 2005, 2:395-400.

17. Olivardia R, Pope HG Jr, Hudson Jl: Muscle dysmorphia in male weightlifters: a case-control study. Am J Psychiatry 2000, 157:1291-1296.

18. Suffolk MT, Dovey TM, Goodwin H, Meyer C: Muscle dysmorphia: methodological issues, implications for research. Eat Disord 2013, 21:437-457

19. Garner DM: The 1997 body image survey results. Psychol Today 1997, 30:30-44.

20. Tucker R, Watkins PL, Cardinal BJ: Muscle dysmorphia, gender role stress, and sociocultural influences: an exploratory study. Res Q Exerc Sport 2011, 82:310-319.

21. Neral SM, Collins J, Gandy MJ, Hampton HL, Morrison JC: Non-cognitive variables and residency choice. J MISS State Med Assoc 2008, 49:327-329.

22. Hughes R, Desbrow B: Aspiring dietitians study: a pre-enrolment study of students motivations, awareness and expectations relating to careers in nutrition and dietetics. Nutr Dietetics 2005, 62:106-109.

23. Grigg M, Arora M, Diwan AD: Australian medical students and their choice of surgery as a career: a review. ANZ J Surg 2013, doi:10.1111/ ans.12389 [Epub ahead of print]. 
24. Donini LM, Marsili D, Graziani MP, Imbriale M, Cannella C: Orthorexia nervosa: validation of a diagnosis questionnaire. Eat Weight Disord 2005, 10:28-32.

25. Hildebrandt T, Langenbucher J, Schlundt DG: Muscularity concerns among men: development of attitudinal and perceptual measures. Body Image 2004, 1:169-181.

26. Varangis E, Folberth W, Hildebrandt $\mathrm{T}$, Langenbucher J: Confirmatory factor analysis for the Muscle Dysmorphic Disorder Inventory among male appearance and performance enhancing drug users. Austin: International Conference on Eating Disorders; 2012. poster ID 3793 http://members. aedweb.org/AM/Template.cfm?Section=Conference_Archive\&Template=/ $\mathrm{CM} /$ ContentDisplay.cfm\&ContentID=3793.

27. Santarnecchi E, Dèttore D: Muscle dysmorphia in different degrees of bodybuilding activities: validation of the Italian version of Muscle Dysmorphia Disorder Inventory and Bodybuilder Image Grid. Body Image 2012, 9:396-403.

28. Garner DM, Olmsted MP, Bohr Y, Garfinkel P: The eating attitudes test: psychometric features and clinical correlates. Psychol Med 1982, 12:871-878.

29. Dotti A, Lazzari R: Validation and reliability of the Italian EAT-26. Eat Weight Disord 1998, 3:188-194.

30. Mintz LB, O'Halloran MS: The Eating Attitudes Test: validation with DSM-IV eating disorder criteria. J Person Ass 2000, 74:489-503.

31. Williams $P$, Hand D, Tarnopolsky A: The problem of screening for uncommon disorders - a comment on the eating attitudes test. Psychol Med 1982, 12:431-434.

32. Abbate-Daga G, Gramaglia C, Malfi G, Pierò A, Fassino S: Eating problems and personality traits. An Italian pilot study among 992 high school students. Eur Eat Disord Rev 2007, 15:471-478.

33. Favaro A, Caregaro L, Tenconi E, Bosello R, Santonastaso P: Time trends in age at onset of anorexia nervosa and bulimia nervosa. J Clin Psychiatry 2009, 70:1715-1721.

34. Hildebrandt T, Schlundt D, Langenbucher J, Chung T: Presence of muscle dysmorphia symptomology among male weightlifters. Compr Psychiatry 2006, 47:127-135.

35. Leone JE: Muscle dysmorphia symptomatology and extreme drive for muscularity in a 23-year-old woman: a case study. I Strength Cond Res 2009, 23:988-995.

36. Goodale KR, Watkins PL, Cardinal BJ: Muscle dysmporphia: A new form of eating disorder? Am J Health Educ 2001, 32:260-266

37. Contesini N, Adami F, Blake M, Monteiro CB, Abreu LC, Valenti VE, Almeida FS, Luciano AP, Cardoso MA, Benedet J, de Assis G, de Vasconcelos F, Leone C, Frainer DE: Nutritional strategies of physically active subjects with muscle dysmorphia. Int Arch Med 2013, 6:25.

38. Aksoydan E, Camci N: Prevalence of orthorexia nervosa among Turkish performance artists. Eat Weight Disord 2009, 14:33-37.

39. Fidan T, Ertekin V, Işikay S, Kirpinar I: Prevalence of orthorexia among medical students in Erzurum, Turkey. Compr Psychiatry 2010, 51:49-54.

40. Ramacciotti CE, Perrone P, Coli E, Burgalassi A, Conversano C, Massimetti G, Dell'Osso L: Orthorexia nervosa in the general population: a preliminary screening using a self-administered questionnaire (ORTO-15). Eat Weight Disord 2011, 16:127-130.

41. Segura-Garcia C, Papaianni MC, Caglioti F, Procopio L, Nisticò CG, Bombardiere L, Ammendolia A, Rizza P, De Fazio P, Capranica L: Orthorexia nervosa: a frequent eating disordered behavior in athletes. Eat Weight Disord 2012, 17:e226-e233.

42. American Dietetic Association. Position of the American Dietetic Association: Nutrition intervention in the treatment of anorexia nervosa, bulimia nervosa, and other eating disorders. J Am Diet Assoc 2006, 106:2073-2082.

43. Patton GC, Selzer R, Coffey C, Carlin JB, Wolfe R: Onset of adolescent eating disorders: population based cohort study over 3 years. BMJ 1999, 318:765-768.

44. Stice E, Ng J, Shaw H: Risk factors and prodromal eating pathology. J Child Psychol Psychiatry 2010, 51:518-525.

doi:10.1186/s12967-014-0221-2

Cite this article as: Bo et al: University courses, eating problems and muscle dysmorphia: are there any associations? Journal of Translational Medicine 2014 12:221.

\section{Submit your next manuscript to BioMed Central and take full advantage of:}

- Convenient online submission

- Thorough peer review

- No space constraints or color figure charges

- Immediate publication on acceptance

- Inclusion in PubMed, CAS, Scopus and Google Scholar

- Research which is freely available for redistribution 